\title{
A Study on the Direction of Spatial Design Based on the Sustainability Checklist
}

\author{
Sooknyung $\mathrm{Ha}$ \\ College of Design, Sangmyung University, Cheonan-si, Chungcheongnam-do, South \\ Korea \\ snha3430@smu.ac.kr
}

\begin{abstract}
With the advancement of science and technology that has continued since the Industrial Revolution, human beings have accelerated the destruction of the natural environment as a consequence of consumption life amid material abundance brought about by mass production. Although resultant environmental changes had some positive aspects for human beings, there have been also negative consequences of environmental changes which in turn have increased social awareness toward the environment. The environmental contamination in contemporary society, which has aggravated to such an extent that it threatens the survival of humanity, has been raised as a global social problem. Sustainable design today represents a systematic concept with well-balanced consideration of environmental, economic, and social aspects of human society, and means the skills, techniques, technologies, and plans involved in the preservation of ecological algorithms and constant maintenance of the ideologies that uphold the dignity of life. Sustainable design is the type of design that respects human beings and nature and fulfills responsibility for society and considers the creation of social, environmental, and economic values, the three major axes underpinning sustainable development. The David Report presented the 'Time to Rethink Design', and the 'Checklist of Sustainable Design'. The Report states that design should be able to contribute, truly improve the quality of everyday life, and at the same time, add to the human experience. That represents a matter of reexamining our values and identities and a matter of negating our blind consumption of brands, new products, and cheap goods. In that way, sustainable design is broadening the scope of responsibilities and obligations related to efficient use of design amid the vigorous formation of networks among corporations, designers, architects, consumers, and institutions that have realized their responsibility in respect of environmental problems and energy depletion. Thus, new design strategies need to be sought by expanding the concept of sustainable design.
\end{abstract}

Keywords: Sustainability, Checklist, Spacial design, Direction

\section{Introduction}

Consumers in contemporary society demand transparency in connection with the sources of products, the influence of products on consumers themselves, and the subsequent disposal of products used. That does not imply that sustainability does nothing [1]. Sustainable design is a success factor for the brand, which creates the power to attract customers and opens up the possibility of new communication.

Article history:

Received (January 7, 2021), Review Result (February 11, 2021), Accepted (March 28, 2021) 
In the case of previous studies subject to sustainable spatial design, research on sustainable spatial design, comparative analysis of green certification system, eco-friendliness evaluation, and the expressional characteristics of design has been continuously conducted, but research on sustainable space applied with reused materials is limited to a very small part, and there is almost no research on a new creative design paradigm from the perspective of regenerating old and abandoned spaces and materials rather than focusing on a new space [2].

The meaning of 'sustainable' is defined as 'human economic activity and culture to preserve the environment and development and use through compatible ways of preserving the environment and natural resources for future generations' [3]. Also, the term currently emphasizes environmental responsibility and is used interchangeably with similar expressions such as 'eco-friendly', 'Eco', and 'Green' when referring to the concept. However, while 'Green' and 'Eco' refer to approaches or design methods that mainly focus on the environment and take into account environmental influences such as materials, technologies, and marketing applied in the product design process, 'Sustainable' differs in its approach in terms of environmental, social and economic impacts of materials, designs, and production processes as well as reuse of resources that can be continuously recycled after disposal [4].

The design field has witnessed the emergence of unprecedented perception and realization called 'conservation of resources' and 'recycle' based on similar concepts such as sustainable design, green design, and eco-design, etc., which connote environment-friendliness. Particularly, the recycling industry is all the more significant for countries, including Korea Eventually, environmental protection and energy consumption reduction can be achieved by delivering the message constantly to Korean consumers that waste mitigation, reuse, and recycling will lead to energy savings and conservation of natural resources, as well as alleviation of climate changes [5].

\section{Checklist for sustainable design}

The 'David Report' presented the 'Checklist for Sustainability' trend report. This checklist is based on the Sustainable Wheel developed by Designboost with a holistic vision for sustainable design [6].

David Report is an influential blog and online magazine that has been writing about trends in the areas where design, culture, and business intersect since 2006. Readers share interest and curiosity in everything from art, architecture, culture, design, innovation, music, sustainability, fashion, and travel. David Carlson, the founder of David Reports, is also the founder of the Design boost conference series, lifestyle shop Carlson Ahnell, and furniture and fashion brand David Design. To this day, he continues to deliver inspiring stories with a wealth of knowledge about his holistic approach to the areas where design, culture, and business intersect.

The Checklist for Sustainable Design, presented in the David Report, is comprised of 7 stages, i.e., the Environmental Influence, Innovative Development, Affectivity, Aesthetics, Multi Quality, Authenticity, and Compatibility. The main details by item are as follows. David Report is an influential blog and online magazine that since 2006 writes about trends in the intersection of design, culture, and business. Our readers share our interest and curiosity in everything from art, architecture, culture, design, and fashion to food, innovation, music, sustainability, and travel [6]. 
Table 1.7 stages for checklist for sustainable design

\begin{tabular}{|c|c|}
\hline 7 Stage & Checklist \\
\hline Environmental Influence & $\begin{array}{l}\text { - Which material resources do we use directly or indirectly } \\
\text { - Do you directly or indirectly produce products that are recycling your product } \\
\text { is costly; reuse is complicated as it demands transport or substantial } \\
\text { deconstruction? } \\
\text { - Is that beneficial to both society and the environment? }\end{array}$ \\
\hline Innovative Development & $\begin{array}{c}\text { - Is your product merely innovative or does it contribute to development? } \\
\text { - How can we break innovation barriers to sustainable development? } \\
\text { - Do you prefer evolution or revolution as a method for creating sustainable } \\
\text { design and a more durable society? } \\
\text { - Is transformation a user-centered design? }\end{array}$ \\
\hline Affectivity & $\begin{array}{l}\text { - How can a product get a meaning; tell a story which goes beyond temporary } \\
\text { lifestyles and makes us associate and recognize? } \\
\text { - How do we design and inspire people to "love" their objects over a lifetime? } \\
\text { - What meaning have: recycling, durable materials, environmentally } \\
\text { friendly production, and use? }\end{array}$ \\
\hline Aesthetics & $\begin{array}{c}\text { - Have we realized that the aesthetic is about immediate but also lasting appeal? } \\
\text { - Are we aware that beauty is something negotiated and what is judged as } \\
\text { beautiful one day might not be the next? } \\
\text { - Is aesthetics as opposed to beauty less related to lifestyle and culture? } \\
\text { - What makes an object truly age with grace? }\end{array}$ \\
\hline 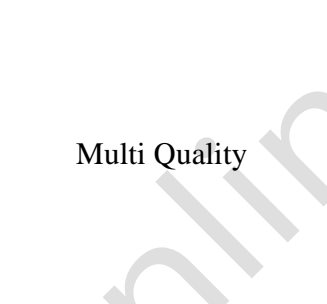 & $\begin{array}{l}\text { - Do we recognize that quality is a multi-capacity? } \\
\text { - Have we tried to specify the capacity of our products beyond the most obvious; } \\
\text { material quality and physical functionality? } \\
\text { - Have we recognized quality as lasting meaning and appeal and considered if } \\
\text { our product makes sense: is meaningful or appears merely strange: new and } \\
\text { cool? } \\
\text { - Whatever we produce pollutes our environment in one way or the other, } \\
\text { can we then afford to buy cheap things? }\end{array}$ \\
\hline Authenticity & $\begin{array}{l}\text { - Is an object which is true to its meaning and its function? } \\
\text { - An object without history is fiction and an object which has not moved on from } \\
\text { history is retrospective. An authentic product could be seen as a mix of the two. } \\
\text { What is your product? } \\
\text { - How do we create authentic experiences that have meaning and value and } \\
\text { a strong sense of cultural identity? }\end{array}$ \\
\hline Compatibility & $\begin{array}{c}\text { - How can we make new products connect? } \\
\text { - How can we better create joint platforms (designers, materials, technology, } \\
\text { etc.)? } \\
\text { - How can we connect history with the present and the future? }\end{array}$ \\
\hline
\end{tabular}




\subsection{Space sustainability through difference and repetition}

As explained above, the space design, examined through the 'Checklist for Sustainability', means that the used material is reapplied to the space to create the designs, and implies the diversity of space created from difference and repetition. The close-up looks at everything which makes up the world shows that the repetitive combinations of fine units are the building blocks of the world. All things, ranging from inorganic substances such as air, soil, rocks to animals and plants such as trees, have their characteristics determined by the repetitive combinations of unit cells. In addition to the repetition by physical structure, the concept of repetition has many implications both artistically and philosophically.

However, repetition in space cannot be explained simply by relying on the concept of art or philosophy alone because both artistic creativity and the functionality of reality need to be taken into consideration. Eventually, a basis was provided by this study for taking an approach based on the philosophical background for sustainability in space. That begins with the 'Difference and Repetition (Différence et Répétition)' authored by Gilles Deleuze. He observed that existence was not effaced or blurred through repetition and duplication, but rather reinforced by the difference between repetitions [7].

Moreover, he mentioned material repetition and mental repetition in connection with the combination of repetition and difference and stated that difference was created from material repetition and that the difference was inherent in mental repetition. In other words, the things emerging in the world of difference match one another and continue to be repeated to create new objects. The difference is created from repetition and both appear together.

Eventually, it can be seen that repetition represents the time repeating itself and arranges and connects the given states positively to create repetition amid the difference and consolidates itself with new things, thus creating an adequate foundation for creation.

Table 2. Space created from difference and repetition [7]

\begin{tabular}{|c|l|}
\hline Gilles Deleuze & \multicolumn{1}{c|}{ Description } \\
\hline Difference and Repetition & $\begin{array}{l}\text { He observed that existence was not effaced or blurred through repetition and } \\
\text { duplication, but rather reinforced by the difference between repetitions Moreover, he } \\
\text { mentioned material repetition and mental repetition in connection with the } \\
\text { combination of repetition and difference and stated that difference was created from } \\
\text { material repetition and that the difference was inherent in mental repetition. }\end{array}$ \\
\hline
\end{tabular}

Architecture is formed through the combination of many different members. Particularly, the materials surrounding the building are often made by repeatedly adding and connecting each unit. In that way, the repeatability manifested in the exterior of the building can be found in the artistic repetition mentioned above, but the repetition associated with production methods can also be identified. For example, the repeatability in the unit, which is produced repeatedly with the same dimensions for greater economic efficiency, could be identified [8].

The tendency that the same materials are repeatedly used for the exterior of architecture may be associated with minimalism. Like minimalism, the works to be introduced in the period ahead use the same industrial materials repeatedly for the exterior. That not only reflects their pursuit of rationality but also represents an attempt to explain their purpose through such mode of arrangement and placement. In the field of philosophy, repetition was to recognize the existence of individuals based on the difference positioned between repetitions. In the field of 
art, repetition represented the efforts to recognize and reflect the reproducibility which characterized the mass consumption society. What distinguishes architecture from art is the close relation of architecture with industrial production.

Eventually, it is found to have something in common with minimalism, given that they used the objects without specific contents as their main materials, rather than using specific images [9]. By using the materials which are repeated simply, the exterior of buildings is perceived differently from the buildings commonly recognized. As a result, the work, created by using the same material repeatedly, is perceived as a single object rather than as a building, and the exterior has the characteristics of objectivity (sachlichkeit) rendered through repetition such as the sequences characteristic of the repetition practiced by minimalist artists [7].

\subsection{Time to rethink design}

Along with that, the David Report presented the 'Time to Rethink Design', following the 'Checklist of Sustainable Design', in 2010. The design has become a major source of contamination as a process and phenomenon. The design, piled upon another, has deteriorated to a state of aesthetic proliferation where it reached a level of destruction to an extent that the meaning, value, and identity are lost. We lead daily lives with an indulgence in new things every day, ranging from cars, mobile devices, computers, lights, chairs to clothing, packaging, food, and toys, losing respect for what has been fully tested, reliable and usable. Fortunately, there has recently been a keen interest in sustainability and energy efficiency which may reflect some penance, but even that is only part of an effort to curb overspending, and the majority of people still reject sustainability as they thrive in affluence [10]. We should face the fact that we are at the tipping point where the equilibrium is disrupted due to climate change and that we have reached a point where the currency of design is devalued, in the same way as currency devalued with the advent of economic crisis, amid sudden waves of drastic changes analogous to the fierce waves of the tsunami that sweeps away and contaminates all things equally, whether they are good or bad, and makes us lose the touch with the reality.

The Report states that design should be able to contribute, truly improve the quality of everyday life, and at the same time, add to the human experience. That represents a matter of re-examining our values and identities and a matter of negating our blind consumption of brands, new products, and cheap goods. In other words, it is related to connecting with emotional values in routine daily life and reconnecting with the well-being of current life. Responsible design is about doing the right things and creating long-term value rather than seeking short-term profits. Responsible design is about building the future based on tolerance instead of greed, promoting care and attention, and making good things that are differentiated, rather than churning out a massive quantity of things. In other words, responsible design is about making the design itself held important [11].

Moreover, would the design, which does not consider human beings, is worth it? The best design is the type of design that incorporates the changing social trends and lifestyles into products and services that respond sensitively to the needs of people. For such a design, a holistic perspective that respects humanistic values and cultural identity would need to be taken. The design does not revolve around lifestyle anymore, but around the lifecycle [5]. Better design assures orderliness and effectiveness without weakening creativity and designers' wit. A better design is the process of fertilization by the transfer of pollen from other individuals, and represents non-linear diversification, and dissolves the given attributes in one place, and transforms them into another. Such kinds of methods can help strike a balance between simplicity and elaborateness and between prudence and boldness while creating designs that 
integrate the past and the present. In short, it is the outcome of new-generation design rooted in a holistic, sustainable, and meaningful view [12].

Table 3. Time to rethink design

\begin{tabular}{|c|c|c|}
\hline Subject & Major Details & Characteristics \\
\hline \multirow{23}{*}{ Time to Rethink Design } & \multirow{3}{*}{ Responsible design [4][24] } & Design creating the long-term value \\
\hline & & Differentiated good design \\
\hline & & Design that is held important \\
\hline & \multirow{5}{*}{$\begin{array}{c}\text { Design that considers human } \\
\text { beings [29] }\end{array}$} & Design reflecting social trends \\
\hline & & Design reflecting the changes in lifestyle \\
\hline & & Design reflecting humanistic values \\
\hline & & Design respecting cultural identity \\
\hline & & Design reflecting the lifecycle \\
\hline & \multirow{5}{*}{ Better design [31] } & Creative design \\
\hline & & Design integrating the past and the present \\
\hline & & Balanced design \\
\hline & & Simple, but the elaborate design \\
\hline & & Prudent and bold design \\
\hline & \multirow{3}{*}{ Timeless design [32] } & Aesthetic design \\
\hline & & High-quality design \\
\hline & & Differentiated design \\
\hline & \multirow{7}{*}{ Transformative design [33] } & Design incorporating creative thinking \\
\hline & & Ingenious design \\
\hline & & Transdisciplinary design \\
\hline & & $\begin{array}{l}\text { A design combining the energy and the } \\
\text { knowledge }\end{array}$ \\
\hline & & Design reconstructing old elements \\
\hline & & Preemptive design \\
\hline & & Knowledge-sharing knowledge \\
\hline
\end{tabular}




\section{Conclusions}

It's important to always have a holistic approach to sustainability. Otherwise, it won't answer its purpose. The recent failure with ethanol fuel is one good example. Something a lot of people thought was a great substitute for gasoline is now heavily questioned. Or look at 'energy efficient' indoor spaces. Advanced techno- logy controls the indoor climate; temperature, ventilation, light, etc. The problem is that we humans react negatively when we are not in charge of our comfort. Could these spaces at all be referred to as sustainable when users are likely to interfere with the system to make it suit themselves? Sometimes these systems even have to be removed because we don't want to live and work at a place that doesn't respect us as individuals with different needs. Therefore, old elements can be reconstructed in new ways while new problems can be thoroughly examined through the acquired wisdom and insight.

Table 4. The direction of spatial design based on the sustainability checklist [13][6]

\begin{tabular}{|c|c|c|}
\hline List for Sustainability & Summary & Evaluation Elements \\
\hline Environmental Influence & $\begin{array}{c}\text { Responsible } \\
\text { Healthy } \\
\text { Resource-economic }\end{array}$ & $\begin{array}{c}\text { Organic / Remade / Cradle to cradle } \\
\text { Reuse / Biogradable }\end{array}$ \\
\hline Innovative Development & $\begin{array}{c}\text { Dynamic } \\
\text { out-of-the-box } \\
\text { differentiation }\end{array}$ & $\begin{array}{l}\text { Re Mix / Creativity / Change } \\
\text { Sympathy / Surprise }\end{array}$ \\
\hline Affectivity & $\begin{array}{l}\text { Emotion-engagement } \\
\text { Feeling-attachment }\end{array}$ & $\begin{array}{l}\text { Love / Rarity / Memory } \\
\text { Reference }\end{array}$ \\
\hline Aesthetics & $\begin{array}{c}\text { Timelessness } \\
\text { Harmony } \\
\text { Value }\end{array}$ & $\begin{array}{c}\text { Essential / Grace / Iconic } \\
\text { Honest }\end{array}$ \\
\hline Multi Quality & $\begin{array}{c}\text { Experiential } \\
\text { Multi capacity } \\
\text { Value } \\
\end{array}$ & $\begin{array}{l}\text { Flexible / Individual / Sensorial } \\
\text { Holistic }\end{array}$ \\
\hline Authenticity & $\begin{array}{l}\text { Identity } \\
\text { Narrative }\end{array}$ & $\begin{array}{c}\text { Patina / Heritage / Storytelling } \\
\text { Genuine / Fantasy }\end{array}$ \\
\hline Compatibility & $\begin{array}{c}\text { Sharing } \\
\text { Interdisciplinary } \\
\text { Seamless } \\
\end{array}$ & $\begin{array}{c}\text { Social / Humanistic / Connecting } \\
\text { Interaction }\end{array}$ \\
\hline
\end{tabular}

\section{References}

[1] S. B. Park, "Consumer behavior”, Myungkyungsa, Seoul, pp.25-26, (2019)

[2] R. B. William, "Sustainable transportation: Problems and solutions," Guilford, New York., pp.58-60, (2010)

[3] http://en.wikipedia.org/wiki/Reuse, Jun 15 (2020)

[4] D. H. Choi, Y. J. Seo, "A study on the urban regeneration planning elements for the pedestrian-friendly city environment," International Journal of Smart Business and Technology, vol.1, no.1, pp. 9-14, (2017) 
[5] S. N. Ha, "Promoting sustainability through web service for materials," Journal of Human-centric Science and Technology Innovation, vol.1, no.1, (2021)

[6] http://davidreport.com/ Jun 20 (2020)

[7] J. F. McLennan, "The philosophy of sustainable design," Ecotone Publishing, Seattle, pp.30-35, (2004)

[8] S. Klaus, "The fourth industrial revolution," CrownPub, Danvers, pp.28-31, (2017)

[9] K. H. Lee, K. Lew, "Creativity research trends in Korea," Asia-Pacific Journal of Educational Management Research, vol.2, no.1, pp.97-102 (2017)

[10] G. G. Parker, M. W. Van Alstyne, S. P. Choudary, "Platform revolution: how networked markets are transforming the economy and how to make them work for you," BrillianceAudio, (2017)

[11] K. R. Merlino, "Building reuse: Sustainability, preservation, and the value of design," M.S. Thesis, Dept. Architecture, University of Washington Press, Seattle, USA, (2018)

[12] D. H. Choi, Y. J. Seo, "A study on the urban regeneration planning elements for the pedestrian-friendly city environment," International Journal of Smart Business and Technology, vol.1, no.1, pp.9-14, (2017)

[13] S. N. Ha, "A study on design expansion of sustainable space and approaches," Journal of Creative Sustainable Architecture and Built Environment, vol.9, no.1, pp.7-12, (2019) 